\title{
Emphasis on Cloud Optimization and Security Gaps: A Literature Review
}

\author{
P. Sanyasi Naidu ${ }^{1}$, Babita Bhagat ${ }^{2}$ \\ ${ }^{1}$ Department of Computer Science and Engineering, Gitam University, Vishakhapatnam, Andhra \\ Pradesh, India \\ ${ }^{2}$ Department of Computer Engineering, Pillai HOC College of Engineering and Technology, Rasayani, \\ Maharashtra, India \\ E-mail: babitabhagat143@gmail.com
}

\begin{abstract}
Cloud computing is emerging as a significant new paradigm in the fields of Service-oriented computing, software engineering, etc. The paper aims to characterize the cloud environment and to study the cloud optimization problems. About 50 papers are collected from the standard journals, and it is first reviewed chronologically to find out the contributions in cloud security. After reviewing, the various challenges addressed in the cloud environment and its performance analysis is discussed. In the next section, the exploration of the meta-heuristic study of cloud optimization is done. The algorithms used in the cloud security challenges are discussed and reviewed. The algorithms such as Genetic Algorithm (GA), Particle Swarm Optimization (PSO), Ant Colony Optimization (ACO) are exploited for the finding the cloud security problems. As the research outcome, case studies are taken and reviewed. Cloud computing is a vast field, and a lot of problems in it had to be addressed and solved.
\end{abstract}

Keywords: Cloud computing, optimization, metaheuristic, Cloud environment.

\section{Introduction}

Cloud computing has emerged from the web-based technologies. It includes the idea of providing computing services and data on demand. The developments in cloud computing platforms help in solving the computationally complex problems in chemistry, meteorology, high-energy physics, astronomy, biology, human brain planning and sensor networks [71-75].The National Institute of Standards and Technology [52] defines cloud computing as "a model for enabling ubiquitous, convenient, on-demand network access to a shared pool of configurable computing resources (e.g., networks, servers, storage, applications, and services) that can be 
rapidly provisioned and released with minimal management efforts or service provider interactions.

Cloud computing has a lot of advantages such as greater resiliency, minimized operational costs [84] including procurement, maintenance and support [5], fastest deployment, pay-per-use, scalability, rapid provisioning, rapid elasticity, utrusionbiquitous network access, hypervisor protection against network attacks, device and location independence, productivity, low cost disaster recovery and secure data storage solutions $[87,88]$, on-demand security controls, real time detection of system tampering and rapid re-constitution of services [51].

Various security issues are found in cloud computing. Information and Communication Technology security issues is an important one to be considered since they face sophisticated attacks using the combinations of the large number of vulnerabilities to penetrate the cloud network [50]. Another security issue is the Reliable Server Assignment under attacks (RSAA) problem which includes determining the locations of servers on an unreliable network to maximize the measure of service reliability for users and interrupting the service [5]. To reduce the increased flow in a disrupting arc in a capacity network, integer programming formulations are introduced in [60]. The capacitated network design issues are addressed in [61], and the flow problem is formulated in [62]. Also, to increase the likelihood of providing the reduced level of flow from a source node to a sink node, the network interdiction problem was studied in [63,64]. Another great threat to cloud computing is the Distributed denial of service attacks in which the attacker control the freedom of information and causes the performance of cloud service to be degraded $[36,85,86]$. Malicious users obtain all the information from virtual machines that co-locate on the same physical server and cause the co-resident attack [4]. Various algorithms are developed to solve the security issues in cloud computing. Genetic algorithm is used to solve the leader problem at the upper level in [65-70]. The particle swarm optimization algorithm is used globally because of its strength, fast convergence and robustness [76-83].

This paper systematically reviews various efforts made in the cloud computing environment to strengthen its efficacy and security. The review is done on nearly 50 research articles (while the total number of supporting references are 88) published in the leading journals of technology in the last 10 years. The articles are accessed by searching for articles with the keywords "cloud security" and its combination with "optimization" and "heuristics". The review and its outcome are further organized as follows. Section 2 firstly reviews the literature in the chronological order and then, presents the security challenges addressed in the cloud environment. Section 3 reveals various optimization problems and their objective models addressed in the cloud environment. Section 4 explores the meta-heuristic procedures used for optimizing the cloud environment by meeting both efficacy and security. Section 5 presents a case study on security threatens on cloud environment as well as the significance of security improvements. Section 6 concludes the review. 


\section{Literature review}

\subsection{Chronological review}

In 2010, Li u et al. [15] had done the module measurement in a virtual environment, and it is compared with the trusted environment. They verified the executables status and added memory watcher module to the virtual machine measurement. In 2011, B ittencourt and Madeira [31] proposed the Hybrid Cloud Optimized Cost scheduling algorithm to identify the resources that have to be leased from the public cloud and added to the private cloud for the execution of workflow within the scheduled time. $\mathrm{H} \mathrm{u}$ u et al. [34] developed an automating cloud resources allocation based on the cost estimation model for optimizing cloud computing infrastructures. $\mathrm{Lu}$ a and $\mathrm{Yow}$ [36] exploited the intelligent water drop algorithm for mitigating the distributed denial of service attacks. For optimization in cloud computing, an intelligent fast-flux swarm network is proposed by them. In 2012, Li et al. [40] proposed two online dynamic resource allocation algorithms for resource optimization in the Infrastructure-as-a-Service cloud system. Li u et al. [47] presented a novel security constraint model for formulating the scheduling problem in distributed data-intensive computing environments. Various algorithms are- multistart PSO, multi-start genetic algorithm and variable neighbourhood PSO are used for the study.

In 2013, X u et al. [3] developed a novel a Double Molecular Structure-based Chemical Reaction Optimization (CRO) method and exploited the CRO to formulate the scheduling of Directed Acyclic Graph (DAG) jobs in heterogeneous computing systems. They also performed simulation experiments to measure its efficiency. $\mathrm{W} \mathrm{u}$ et al. [10] have worked on cloud workflow systems and developed a strategy in market-oriented hierarchical scheduling. Based on this strategy, they proposed a package based random scheduling algorithm. They also used other metaheuristic algorithm and analyzed the scheduling algorithms. Li in et al. [21] exploited the cloud computing technologies and designed a privacy-preserving mobile health monitoring system. They also developed a new private proxy reencryption to shift the computational complexity of the involved parties.

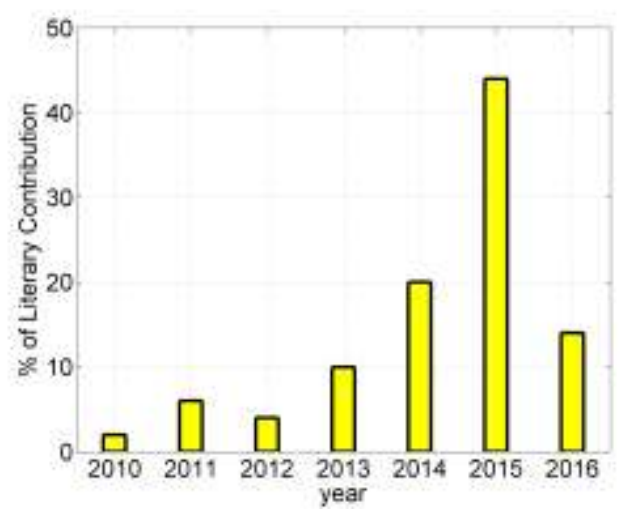

Fig. 1. Chronological review of contributions in the cloud security 
Yildirim, Kimb and Kosar [37] developed a model to find out the optimal sampling size based on the cloud data and the capacity of the network. $\mathrm{Ch}$ andras e kara n, Mur a lid har and Dix it [41] have worked on optimization of machine process using the cloud computing techniques which provides on-demand computing services and data. In 2014, Karampaglis, Gounaris and Manolopoulos [1] developed a bi-objective query cost model which can be applied for queries executed over resources with the multiple crowd providers. Chen et al. [8] proposed a co-evolutionary negotiation process between service consumer and service provider over the quality of service requirements in cloud computing. Koehler [14] introduced the optimization of resource utilization using the selffiguring adaptive framework and integrated into the Vienna Cloud Environment for scientific applications on top of Cloud technologies. $\mathrm{S} \mathrm{h} \mathrm{u}, \mathrm{W}$. W a n g and Y. W a n g [13] proposed an improved clonal selection algorithm for meeting the service level agreement requested by the users and using Cloud Sim toolkit; they analysed its performance. Folino and Pisani [18] implemented a new generating model framework using the genetic programming for making automatic decisions on the offloading of the mobile applications. Arango et al. [24] exploited the cloud computing capabilities and developed the evolutionary algorithms for analyzing and making decisions in water distribution systems. Zh u and Gong [29] developed a new fuzzy authorization scheme by exploiting the Ciphertext-Policy Attribute-Based Encryption and OAuth to enhance the scalability and flexibility of the file sharing. Ge et al. [35] proposed a sharing system known as Lineage-Signature to find a solution to the Multiple Query optimization problem in the cloud computing. F a n g et al. [39] proposed a novel user-side optimization process-Off-the-Cloud Service Optimization method for efficient service provision. S h i and B o [42] focused on studying the physical layer security in downlink heterogeneous Cloud radio access network systems.

In 2015, Che $\mathrm{n}$ et al. [2] had worked on cloud security and proposed a cloud computing-based network monitoring and threat detection system using Hadoop, MapReduce, and Spark. A. Konak, S. Konak and Snyder [5] developed the Game-Theoretic Genetic Algorithm and compared its performance with the nested genetic algorithms for maximizing the network reliability and simultaneously reducing the reliable server assignment problem. B harathi and Sharifian [7] used hybrid genetic algorithm and PSO to develop a newly tuned support vector regression method for cloud computing elasticity. Karami and Sapata [9] detected the denial of service attacks and adaptive mitigation reaction in Named data networking by using a multiobjective evolutionary optimization algorithm with PSO. $\mathrm{B}$ a m a k a n et al. [11] improved the performance of Intrusion detection system by implementing the simple optimization technique- PSO and multiple criteria linear programming. Singh, Juneja and Malhotra [12] developed a new Agentbased Automated Service Composition Algorithm which includes request processing and automated service composition phases, thereby optimizing the resource allocation and reducing the cost of virtual machines. J i a n g et al. [16] have worked on high energy efficient routing in energy-efficient networks for cloud computing and optimized the link sleeping method to increase the number of sleeping links. 
Grzonka et al. [17] developed a model of security-driven grid schedulers with Artificial Neural Network for Solving the problem of scheduling. S in g h, J u n ej a and Malhotra [19] proposed an Autonomous Agent-Based Load Balancing Algorithm to provide dynamic load balancing for the cloud environment. P a cin i, Mateos and Garino [20] have worked on private clouds to run the scientific experiments of multiple data using the Infrastructure as a Service model and evaluated the cloud scheduler based on the Ant colony optimization. F. Moghadd a m, R. Mogh add a m and Cheriet [22] developed a new genetic algorithm-multi-level grouping GA for analyzing the carbon footprint reduction, thereby reducing the Green House Gas emissions. M a m u n et al. [23] developed a cloud-based framework for identifying the Parkinson patients by their voice samples through their phones, thereby checking their Dysphonia over the cloud. H u o et al. [26] introduced the Discrete Gbest-guided Artificial Bee Colony algorithm for optimizing the cloud service composition. Suguna and Suhasini [27] performed the analysis of massive data storage process using the Enriched MultiObjective Optimization Model for Efficient Disaster Recovery in a cloud environment. $\mathrm{Na}$ vi mi pou r et al. [28] proposed a new Expert Cloud framework for the cloud users to share the human resource skills, knowledge and visualization. They also introduced the Expert Cloud employing Internet infrastructures and Cloud computing concepts. Rao and Thilakam [32] have worked on server consolidation in managing cloud data centre. They developed RFAware Server Consolidation approach for reducing the number of physical servers. Jula, Othman and Sundararajan [33] proposed CSSICA approach with PROCLUS classifier to make advances toward the lowest possible service time and developed an improved imperialist competitive algorithm. W ang et al. [38] introduced a security-aware model and applied meta-heuristic which is based on the supercomputer hybrid architecture for heterogenous cloud scheduling. S u n et al. [43] optimized the cloud resource allocation for offering web applications using the software as a service model in the cloud and developed a modelling frameworkResource optimization, Allocation and Recommendation System for optimization. Ze n g, V e e ravalli and Li [44] used immovable dataset concept and developed a Security-Aware and Budget-Aware workflow scheduling strategy, to provide customers with shorter makespan and high-quality security services. $\mathrm{Hu}$ a m g et al. [45] have worked on Cloud Manufacturing (CMfg) platform for group enterprises (GE) and proposed conflict resolution mathematical model based on the Ant colony optimization algorithm and serial schedule generation scheme. Zin ne dine [50] proposed a cloud security framework for mitigating the vulnerabilities and had done cost optimization using Cuckoo search algorithm with Levy flight as random walks and thereby balanced the IT security coverage.

In 2016, $\mathrm{H}$ a $\mathrm{n}$ et al. [4] introduced a defence mechanism to get away from the security risks and eliminated various types of side channels and preventing co-residence by using cluster analysis and semi-supervised learning techniques. Alkhanak et al. [25] analyzed the problem of cost optimization in Scientific Workflow Scheduling (SWFS) by studying the traditional SWFS in cloud and grid computing and provided the cost optimization classification of SWFS. 
A h mad et al. [6] proposed a Hybrid genetic algorithm for solving the work flow scheduling problem and also used for optimizing the load balance for maximum resource utilization. Palmieri et al. [30] used the greedy randomized adaptive search procedure, augmented by path re-linking to re-optimize the communication paths between virtual machines and big data sources, thereby increasing the performance of service quality. Sindhu, Gill and S o od [46] have worked on H1N1 infected patients and proposed a cloud computing architecture for predicting the infected patients and the prevention measures to control the infection rate and to stop the outbreak of H1N1. Abdullahi, Ngadi and Abdulhamid [48] developed a meta-heuristic optimization technique-Discrete Symbiotic Organism Search algorithm for optimal, efficient task scheduling on cloud resources. Mehrotra et al. [49] introduced a framework of autonomic performance management and developed a distributed control based approach for interactive bidding of cloud computing resources and to maintain the service level agreements. Fig. 1 shows the year-wise percentage of contributions in the cloud security. About $44 \%$ of the works have been done in the year 2015, and it is in the highest range. A lot of works are also done in 2016. Only 1\% work is done in 2010 corresponding to cloud security. The figured data predicts the recent advancements and research in the area of cloud computing.

\subsection{Review of Cloud environment}

Karampaglis, Gounaris and Manolopoulos [1] solved the problem of which cloud providers to run a task in the cloud environment. $\mathrm{Chen}$ et al. [2] provided the highly secured critical infrastructure system and threat monitoring system to perform functions for health and security. $\mathrm{Xu}$ et al. [3], $\mathrm{A} \mathrm{hmad}$ et al. [6], Grzonka et al. [17], Pacini, Mateos and Garino [20], Abdullahi, $\mathrm{Ngadi}$ and Abdulhamid [48] Liu et al. [47], Li et al. [40], Alkhanak et al. [25], Wang et al. [38], Bittencourt and Madeira [31], Wu et al. [10] and $\mathrm{Li}$ et al. [40] formulated and solved the task scheduling problem on cloud computing system in modern distributed environments. Han et al. [4] and A. Konak, S. Konak and Snyder [5] worked on finding a solution to the coresident attacks in cloud computing. B arati and Sharifian [7] worked on increasing the accuracy of cloud load prediction. $\mathrm{Karami}$ and $\mathrm{Z}$ apat a [9], B a makan et al. [11], Konak et al. [5] and Lua and Yow [36] mitigated the Denial of service attacks and enhanced the accuracy of attacks detection. S ingh, Juneja and Malhotra [12], Shu, W. Wang and Y. Wang [13], F. Moghaddam, R. Moghaddam and Cheriet [22], Mehrotra et al [49], $\mathrm{Sun}$ et al [43], Fang et al. [39], Huu et al. [34], Koehler [14] and Jiang et al. [16] solved the problem of energy-efficient resource allocation in cloud computing, thereby minimizing the cost of operation. Folino and Pisani [18] S ingh, Juneja and Malhotra [19] tackled the problem of load balancing in computing environments. Mamun et al. [23] improved the speech-signal processing and recognition system to detect the Parkinson's disease in cloud-based framework. A rang o a et al. [24] found a solution to the decision-making system which is based on cloud environment in Water distribution systems. H u o et al. [26] 
tackled the problem of facing a large number of cloud application services. S u g u $\mathrm{n}$ a and Suhasini [27] analyzed the cloud efficient disaster recovery process. $\mathrm{N}$ avimip our et al. [28] worked on sharing the skill, knowledge and experience and visualization of human resources. Zhu and Gong [29] enhanced the scalability and flexibility of file sharing in a cloud network. Palmieri et al. [30] worked on the re-optimization problem. Rao and Thilagam [32] found a solution in reducing both residual resource fragmentation and a number of active physical servers. J u la, Oth m a n, and S und ar a r a j a n [33] provided satisfying, and value-added cloud composite services for service time optimization. $\mathrm{Ge}$ et al. [35] found a solution to multiple query optimization problems. Y il d i i m, K i m b and Kosar [37] worked on cloud optimization services. Chandrase karan, M ura lidh ar and Dix it [41] worked on the feasibility of using cloud computing. $\mathrm{Shi}$ and B o [42] characterized the physical layer security in the downlink. Ze ng, Veeravalli and Li [44], Liu et al. [15], Chen et al. [8] and Lin et al. [21] ensured the high quality of security and service with minimizing operational cost. $\mathrm{Hu}$ ang et al. [45] analysed the service requirement conflict resolution in cloudbased system. Sindhu, Gill and S ood [46] solved the outbreak problem and keep track of virus strain. Zin ed dine [50] worked on solving the vulnerabilities coverage and cost optimization.

Table 1. Challenges addressed in the cloud environment

\begin{tabular}{|c|c|c|c|c|c|c|c|}
\hline $\begin{array}{l}\text { Experts } \\
\text { [Citation] }\end{array}$ & $\begin{array}{c}\text { Task } \\
\text { scheduling } \\
\text { problem }\end{array}$ & $\begin{array}{c}\text { Co- } \\
\text { resident } \\
\text { attack }\end{array}$ & $\begin{array}{l}\text { Service } \\
\text { attack }\end{array}$ & \begin{tabular}{|} 
Energy- \\
efficient \\
resource \\
allocation
\end{tabular} & $\begin{array}{c}\text { Load } \\
\text { balancing }\end{array}$ & $\begin{array}{l}\text { Quality } \\
\text { service }\end{array}$ & Other challenges \\
\hline $\begin{array}{l}\text { Karampaglis, } \\
\text { Goun aris and } \\
\text { M anolopoulos }\end{array}$ & & & & & & & $\begin{array}{l}\text { Cloud providers } \\
\text { running task }\end{array}$ \\
\hline Che $n$ et al. [2] & & & & & & & $\begin{array}{c}\text { Critical infrastructure } \\
\& \text { threat monitoring } \\
\text { system }\end{array}$ \\
\hline $\mathrm{Xu}$ et al. [3] & $\checkmark$ & & & & & & - \\
\hline A h mad et al. [6] & $\checkmark$ & & & & & & - \\
\hline Grzonka et al. [17] & $\checkmark$ & & & & & & - \\
\hline $\begin{array}{l}\text { Pacin i, M a te os } \\
\text { and G arin o [20] }\end{array}$ & $\checkmark$ & & & & & & - \\
\hline $\begin{array}{l}\text { Abdullahi, Ngadi } \\
\text { and Abdulhamid [48] }\end{array}$ & $\checkmark$ & & & & & & - \\
\hline Li u et al. [47] & $\checkmark$ & & & & & & - \\
\hline Li $\quad$ et al. [40] & $\checkmark$ & & & & & & - \\
\hline A $1 \mathrm{khanak}$ et al. [25] & $\checkmark$ & & & & & & - \\
\hline W a $n$ g et al. [38] & $\checkmark$ & & & & & & - \\
\hline $\begin{array}{l}\text { Bit t encourt } \\
\text { and M adeira [31] }\end{array}$ & $\checkmark$ & & & & & & - \\
\hline W u et al. [10] & $\checkmark$ & & & & & & - \\
\hline $\mathrm{H}$ a n et al. [4] & & $\checkmark$ & & & & & - \\
\hline $\begin{array}{l}\text { A. Kon a k, S. Kon a k } \\
\text { and S n y d e r [5] }\end{array}$ & & $\checkmark$ & & & & & - \\
\hline $\begin{array}{l}\text { B arati } \\
\text { and Sharifian [7] }\end{array}$ & & & & & & & $\begin{array}{l}\text { Cloud load } \\
\text { prediction }\end{array}$ \\
\hline $\begin{array}{l}\text { Karamagi and } \\
\text { Zapata }[9]\end{array}$ & & & $\checkmark$ & & & & 1 \\
\hline B a m a k a n et al. [11] & & & $\checkmark$ & & & & - \\
\hline Lu a and Yow [36] & & & $\checkmark$ & & & & - \\
\hline
\end{tabular}


Table 1. Con tin u ed

\begin{tabular}{|c|c|c|c|c|c|c|c|}
\hline $\begin{array}{l}\text { Experts } \\
{[\mathrm{Citation}]}\end{array}$ & $\begin{array}{c}\text { Task } \\
\text { scheduling } \\
\text { problem }\end{array}$ & $\left\{\begin{array}{c}\text { Co- } \\
\text { resident } \\
\text { attack }\end{array}\right.$ & $\begin{array}{l}\text { Service } \\
\text { attack }\end{array}$ & \begin{tabular}{|l|} 
Energy- \\
efficient \\
resource \\
allocation
\end{tabular} & $\begin{array}{c}\text { Load } \\
\text { balancing }\end{array}$ & $\begin{array}{l}\text { Quality } \\
\text { service }\end{array}$ & Other challenges \\
\hline $\begin{array}{l}\text { S in g h, J un e ja } \\
\text { and M a lhotr a [12] }\end{array}$ & & & & $\checkmark$ & & & - \\
\hline $\begin{array}{l}\text { S h u, W. W a n g } \\
\text { and Y.W a n g [13] }\end{array}$ & & & & $\checkmark$ & & & - \\
\hline $\begin{array}{l}\text { F. Moghadd a m, R. } \\
\text { Moghaddam and } \\
\text { Cheriet [22] }\end{array}$ & & & & $\checkmark$ & & & - \\
\hline Mehrotra et al. [49] & & & & $\checkmark$ & & & - \\
\hline S u n et al. [43] & & & & $\checkmark$ & & & - \\
\hline F a n g et al. [39] & & & & $\checkmark$ & & & - \\
\hline $\mathrm{H} \mathrm{u} \mathrm{u} \mathrm{et} \mathrm{al.} \mathrm{[34]}$ & & & & $\checkmark$ & & & - \\
\hline Ko e h le r [14] & & & & $\checkmark$ & & & - \\
\hline J i a n g et al. [16] & & & & $\checkmark$ & & & - \\
\hline $\begin{array}{l}\text { Folin o } \\
\text { and Pis a n i [18] }\end{array}$ & & & & & $\checkmark$ & & - \\
\hline $\begin{array}{l}\text { S in g h, J un e ja } \\
\text { and M a lho tra [19] }\end{array}$ & & & & & $\checkmark$ & & - \\
\hline M a mu n et al. [23] & & & & & & & $\begin{array}{l}\text { Speech-signal } \\
\text { processing }\end{array}$ \\
\hline A r a ng o a et al. [24] & & & & & & & $\begin{array}{c}\text { Decision-making } \\
\text { system }\end{array}$ \\
\hline H u o et al. [26] & & & & & & & $\begin{array}{l}\text { Facing large number } \\
\text { of cloud application } \\
\text { service }\end{array}$ \\
\hline $\begin{array}{l}\text { S u gun a } \\
\text { and Suh a s in i [27] }\end{array}$ & & & & & & & $\begin{array}{c}\text { Cloud efficient } \\
\text { disaster recovery }\end{array}$ \\
\hline $\mathrm{N}$ a vi mi p ou r et al. [28] & & & & & & & $\begin{array}{l}\text { Hr visualization } \\
\text { and sharing data }\end{array}$ \\
\hline $\begin{array}{l}\mathrm{Zh} \mathrm{u} \\
\text { and G o n g [29] }\end{array}$ & & & & & & & $\begin{array}{c}\text { Scalability \& Flexibility } \\
\text { of file sharing }\end{array}$ \\
\hline P a $1 \mathrm{~m}$ i e ri et al. [30] & & & & & & & $\begin{array}{c}\text { Re-optimization } \\
\text { problem }\end{array}$ \\
\hline $\begin{array}{l}\mathrm{R} \text { a o } \\
\text { and } \mathrm{Th} \text { i } 1 \text { a g a m [32] }\end{array}$ & & & & & & & $\begin{array}{c}\text { Residual resource } \\
\text { fragmentation and } \\
\text { number of active } \\
\text { physical servers } \\
\text { reduction }\end{array}$ \\
\hline $\begin{array}{l}\text { J u } 1 \text { a, O th m a n, and } \\
\text { S und a r a r a j a n }\end{array}$ & & & & & & & $\begin{array}{l}\text { Service time } \\
\text { optimization }\end{array}$ \\
\hline G e et al. [35] & & & & & & & $\begin{array}{c}\text { Multiple query } \\
\text { optimization problem }\end{array}$ \\
\hline $\begin{array}{l}\text { Chandrase karan, } \\
\text { M uralid h a } \\
\text { and Dixit [41] }\end{array}$ & & & & & & & $\begin{array}{l}\text { Feasibility of using } \\
\text { cloud computing }\end{array}$ \\
\hline $\begin{array}{l}\text { Y i ld i r i m, K i m b } \\
\text { and K o s a r [37] }\end{array}$ & & & & & & & $\begin{array}{c}\text { Cloud optimization } \\
\text { service }\end{array}$ \\
\hline $\mathrm{S} \mathrm{h} \mathrm{i} \mathrm{and} \mathrm{B} \mathrm{o} \mathrm{[42]}$ & & & & & & & $\begin{array}{c}\text { Characterization of } \\
\text { physical layer security } \\
\text { in the downlink. }\end{array}$ \\
\hline $\begin{array}{l}\text { Z e n g, V e e r a v a } 11 \mathrm{i} \\
\text { and Li [44] }\end{array}$ & & & & & & $\checkmark$ & ( \\
\hline Li u et al. [15] & & & & & & $\checkmark$ & - \\
\hline C h e n et al. [8] & & & & & & $\checkmark$ & - \\
\hline Li n et al. [21] & & & & & & $\checkmark$ & - \\
\hline $\mathrm{Hu}$ a n g et al. [45] & & & & & & & $\begin{array}{l}\text { Service requirement } \\
\text { conflict resolution }\end{array}$ \\
\hline $\begin{array}{l}\text { S ind h u, Gill and } \\
\text { S o o d [46] }\end{array}$ & & & & & & & $\begin{array}{l}\text { Outbreak problem } \\
\text { And keep track } \\
\text { of virus strain }\end{array}$ \\
\hline Zin ed dine [50] & & & & & & & $\begin{array}{l}\text { Vulnerability Coverage } \\
\text { and cost optimization }\end{array}$ \\
\hline
\end{tabular}


The Equations (1)-(5) represents the task scheduling problem constraints referred from [89]. Equation (1) makes sure that each task is performed and Equation (2) ensures the successive tasks, all predecessors are completed before the successor initiates. Equation (3) illustrates the add up demand of all the tasks $a$ at a time period $t$, and it is indicated as $d_{t}$. Equation (4) makes sure that $x_{a t}$ are binary while $d_{t}$ nonnegative and integer according to the Equation (5). Nevertheless, the integrality condition can be relaxed due to $d_{t}$ will always an integer with $R_{a}$ being an integer and $x_{a \tau}^{\text {start }}$ being binary according to Equation (3).

$$
\begin{aligned}
& \sum_{t=T_{a}^{\text {earitiest }}}^{T_{a}^{\text {latest }}} x_{a t}^{\text {start }}=1 \quad \forall a \in A,
\end{aligned}
$$

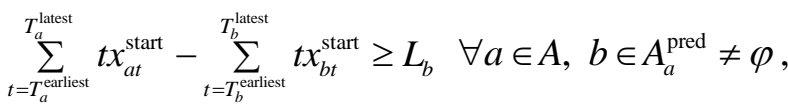

$$
\begin{aligned}
& \sum_{a \in A} R_{a}\left(\sum_{\tau=\max \left\{T_{a}^{\text {eariest }} ; t-L_{a+1}\right\}}^{\min \left\{t ; T_{a}^{\text {latest }}\right\}} x_{a \tau}^{\text {start }}\right)=d_{t} \forall t \in J, \\
& x_{a t}^{\text {start }} \in\{0,1\} \quad \forall a \in A, t \in J_{a}^{\text {start }}, \\
& d_{t} \in N_{0} \quad \forall t \in J,
\end{aligned}
$$

where, $R_{a}$ indicates the resource demand of task $a$ for each time period (i.e., No of workers), $L_{a}$ indicates the Length of the task $a$ in time periods, $T_{a}^{\text {earliest }}$ indicates the earliest start time of the task $a$ and $T_{a}^{\text {latest }}$ indicates the latest start time of the task $a$.

In quality of service, the response time measures the delay time in seconds. The probability that the service is accessible is known as the availability, and the probability that a request is responded correctly is termed as reliability. The execution fee per request is known as the Price (Cost). The average user rating for the service is called as the Rating.

The Equation (6) illustrates the energy efficient resource allocation. Here, assume the $\mathrm{Idle}_{i}$ indicates the time of the resource $r_{i} . L(j)$ represents a set of DVFS levels used for the tasks assigned to resource $r_{i}, v_{\min }$ and $f_{\min }$ represents the voltage and frequency while the resource $r_{i}$ transition to the sleep mode in the idle time, and $\lambda$ indicates the load factor, subsequently the cumulative energy used by the resource $r_{i}$ for the completion of all tasks assigned to the resource is illustrated in Equation (6). The energy consumed for the offloading process and waiting for the end of the computation on the cloud sever is illustrated as Equation (7).

$$
\begin{gathered}
E_{i}=\gamma \times f \times\left\{\sum_{j \in T(i) k \in L(j)}\left(\left[\left(v_{k}(i)\right)_{j}\right] 2 \times C T(i, j)\right)+v_{\min }(i) \times f_{\min }(i) \times \text { Idle }_{i}+\lambda\right\}, \\
E_{c}=P_{i} \times \frac{C}{S}+P_{t r} \times \frac{D}{B},
\end{gathered}
$$

where, $D$ indicates the cloud system and $B$ indicates the network bandwidth, $C$ indicates the number of instructions required by the computation, $S$ indicates the speed, $P_{i}$ indicates idle, $P_{t r}$ indicates the sending and receiving data. Besides, the co-resident attacks in cloud computing are the main threat to data confidentiality. 
Equation (8) illustrates the service attack throughput [90]. Here, RTO indicates the Re-transmission Time Out, $T$ indicates the time period:

$$
\rho(T)=\frac{\left[\frac{\min \mathrm{RTO}}{T}\right] T-\min \mathrm{RTO}}{\left[\frac{\min \mathrm{RTO}}{T}\right] T} .
$$

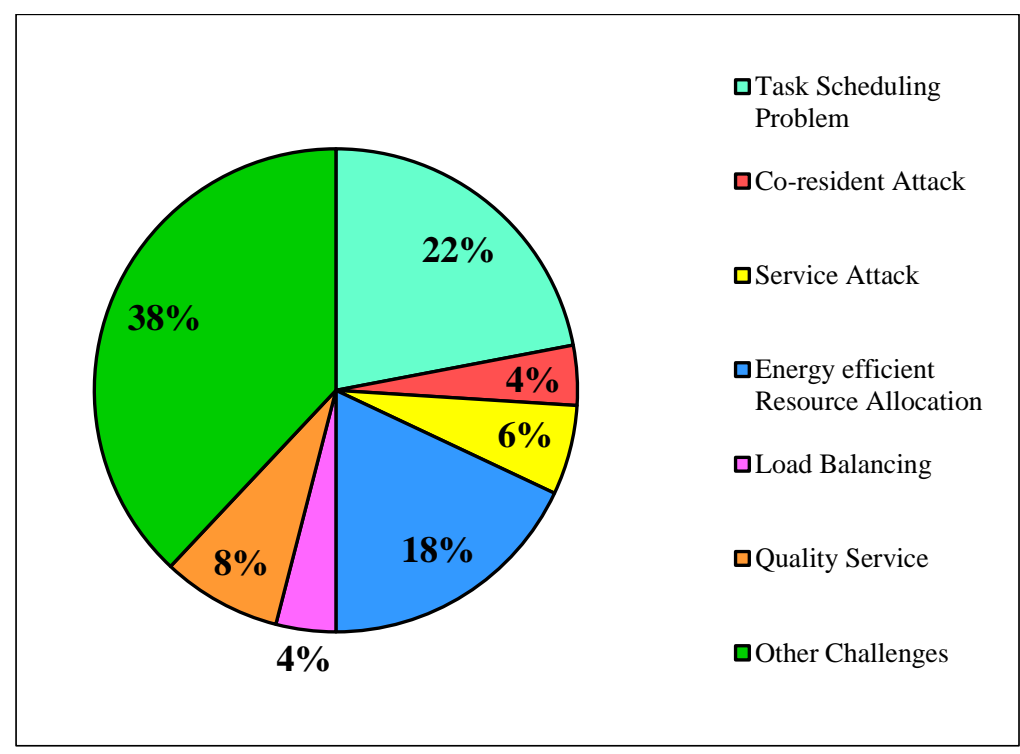

Fig. 2. Analysis on cloud optimization for achieving various objective models

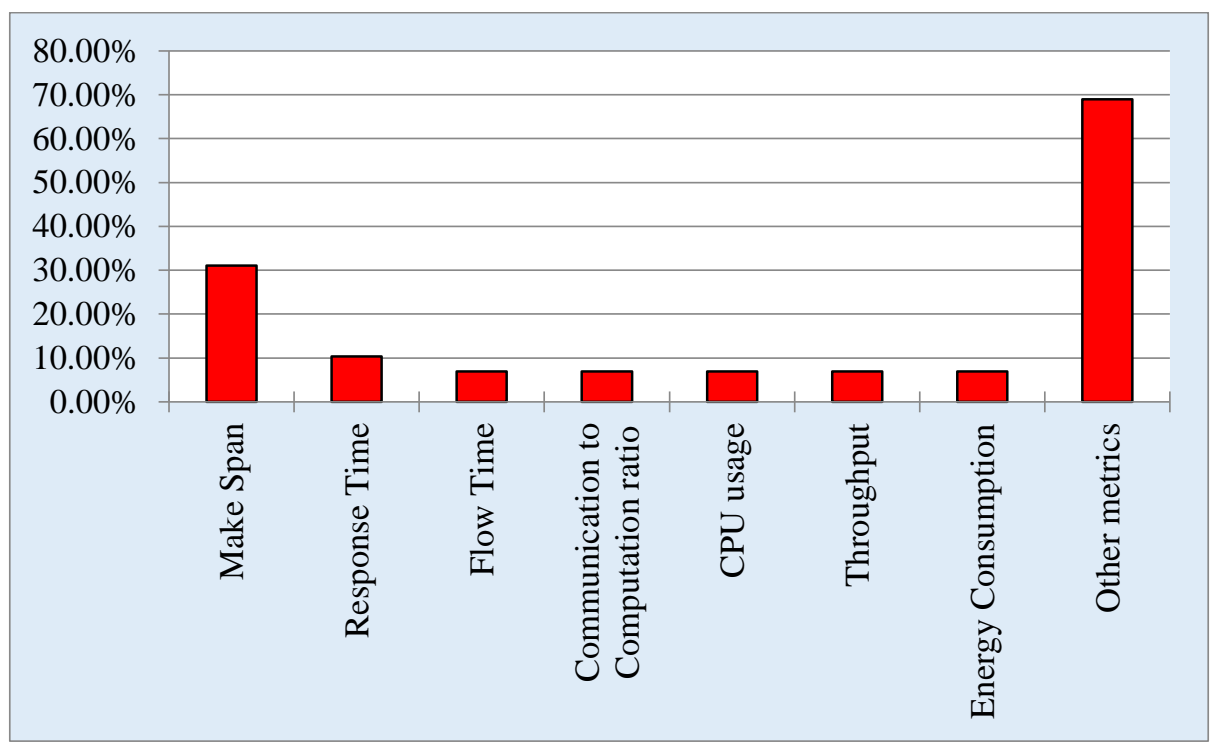

Fig. 3. Analysis on cloud optimization deployed for improving performance measures 


\section{Cloud optimization}

\subsection{Objective models}

- The task scheduling problem in cloud computing environment has been optimized in $[48,3,6,25,34,40,47]$. Optimization has been done in $[43,30,50,31]$ to minimize the operational cost and to ensure the performance and quality of service. For designing the chemical reaction operation, various optimization processes has been used in [3]. Cloud load prediction optimization has been done in [7]. The mitigation of DOS attacks in Named data networking has been optimized for better performance in [9]. Improvising the performance of MCLP classifier has been enhanced with the optimization techniques in [11]. The resource provisioning for cloud computing [12] and cloud service resource management for efficient service delivery [39] has been optimized. Optimization techniques have been used in cloud manufacturing platform for group enterprise [42] and multi-pass machining [41]. Running massive data analysis queries [35], cloud computing service composition [33] and scientific application on top of cloud technologies [14] has been optimized. The estimation capacity of the network [37] and ensuring autonomous coordination [36] have been optimized. Optimization has been used to improve energy efficient networks for cloud computing [16, 13], disaster recovery in cloud environment [27] and balancing throughput and response time in online scientific clouds [20].

Table 1 illustrates the various challenges in the cloud environment. Among the problems addressed, Task scheduling problem seems to be the major problem focused in cloud computing research, and it was found to be $22 \%$ among the literature reviewed. The energy efficient allocation resource has been taken as a challenge and addressed in $18 \%$ of the works in cloud computing. Other problems considered include Quality service, load balancing, service attack and co-resident attack. Quality service problem is shown in $8 \%$ of the reviewed papers. About $4 \%$ of the works have been done to solve the problem of load balancing. The service attack problem is considered in about $6 \%$ of the papers reviewed. Also, the co-resident attack is discussed in $4 \%$ of the collected reviews. The analysis of the contributions to solving the objective models is illustrated in Fig. 2.

\subsection{Performance study}

Table 2 shows the various performance analyses for cloud optimization. Makespan has been used as the performance parameter for cloud optimization in most of the works, and it was about $31 \%$ of the 29 cloud optimization papers. 
Table 2. Various performance analysis for cloud optimization

\begin{tabular}{|c|c|c|c|c|c|c|c|c|}
\hline $\begin{array}{l}\text { Experts } \\
\text { [Citation] }\end{array}$ & $\begin{array}{l}\text { Make } \\
\text { span }\end{array}$ & $\begin{array}{c}\text { Response } \\
\text { time }\end{array}$ & $\begin{array}{l}\text { Flow } \\
\text { time }\end{array}$ & $\begin{array}{c}\text { Communication } \\
\text { to computation } \\
\text { Ratio }\end{array}$ & $\begin{array}{c}\mathrm{CPU} \\
\text { usage }\end{array}$ & $\begin{array}{c}\text { Through } \\
\text {-put }\end{array}$ & $\begin{array}{c}\text { Energy } \\
\text { consumption }\end{array}$ & $\begin{array}{l}\text { Other } \\
\text { metrics }\end{array}$ \\
\hline $\mathrm{Xu}$ et al. [3] & $\checkmark$ & & & $\checkmark$ & & & & - \\
\hline $\begin{array}{l}\text { A. Kon a k, } \\
\text { S. Kon a k } \\
\text { and Snyder [5] }\end{array}$ & & & & & & & & $\begin{array}{c}\text { Critical service } \\
\text { rate }\end{array}$ \\
\hline A h m a d et al. [6] & & & & $\checkmark$ & & & & $\begin{array}{c}\text { Average } \\
\text { Schedule Length }\end{array}$ \\
\hline $\begin{array}{l}\text { Barati and } \\
\text { Sharifian [7] }\end{array}$ & & & & & $\checkmark$ & & & $\begin{array}{l}\text { Prediction error, } \\
\text { memory usage }\end{array}$ \\
\hline $\begin{array}{l}\mathrm{K} \text { ar a mi and } \\
\mathrm{K} \text { a p a t a }[9]\end{array}$ & & & & & & $\checkmark$ & & $\begin{array}{c}\text { Interest } \\
\text { satisfaction } \\
\text { ratio, PIT usage, }\end{array}$ \\
\hline B a ma k a n et al. [11] & & & & & & & & $\begin{array}{c}\text { Accuracy, False } \\
\text { Alarm Rate }\end{array}$ \\
\hline $\begin{array}{l}\text { S ing h, Ju ne ja } \\
\text { and M a lhotra [12] }\end{array}$ & & $\checkmark$ & & & & & & $\begin{array}{c}\text { Cost of } \\
\text { Resources }\end{array}$ \\
\hline $\begin{array}{l}\text { S h u, W. W a n g } \\
\text { and Y.W a n g [13] }\end{array}$ & $\checkmark$ & $\checkmark$ & & & & & $\checkmark$ & 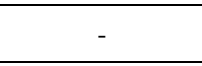 \\
\hline Koeh le r [14] & & & & & & & & $\begin{array}{l}\text { Resource utility } \\
\text { ratio }\end{array}$ \\
\hline $\mathrm{J}$ i a n $\mathrm{g}$ et al. [16] & & & & & & & & $\begin{array}{c}\text { Energy } \\
\text { efficiency }\end{array}$ \\
\hline $\begin{array}{l}\mathrm{Pac} \text { a i i, M a t e o s } \\
\text { and G a rin o [20] }\end{array}$ & $\checkmark$ & & $\checkmark$ & & & & & - \\
\hline A $1 \mathrm{khanak}$ et al. [25] & $\checkmark$ & & & & & & & - \\
\hline $\begin{array}{c}\text { S uguna and } \\
\text { S uhasini }[27] \\
\end{array}$ & & & & & & & & Scheduling time \\
\hline Pa $1 \mathrm{mi}$ er i et al. [30] & & & & & & & & - \\
\hline $\begin{array}{c}\text { Bittencourt } \\
\text { and Madeira }\end{array}$ & $\checkmark$ & & & & & & & $\begin{array}{c}\text { Desired } \\
\text { Execution time }\end{array}$ \\
\hline $\begin{array}{c}\text { J u } 1 \text { a, O th } \mathrm{m} \text { a n, and } \\
\text { S u n d a r a r a j a n } \\
{[33]}\end{array}$ & & & & & & & & 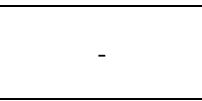 \\
\hline $\mathrm{H} \mathrm{u} \mathrm{u} \mathrm{et} \mathrm{al.} \mathrm{[34]}$ & $\checkmark$ & & & & & & & $\begin{array}{c}\text { Deployment } \\
\text { time }\end{array}$ \\
\hline Ge et al. [35] & & & & & & & & $\begin{array}{l}\text { Coverage, Scale- } \\
\text { up, Optimization } \\
\text { analysis }\end{array}$ \\
\hline Lu a and Yow [36] & & & & & & & & $\begin{array}{l}\text { Latency } \\
\text { measure }\end{array}$ \\
\hline $\begin{array}{r}\text { Y i l d i r i m, K i m b } \\
\text { and Kos a r [37] } \\
\end{array}$ & & & & & & & & $\begin{array}{c}\text { Size selection } \\
\text { error rate }\end{array}$ \\
\hline W a $n \mathrm{~g}$ et al. [38] & $\checkmark$ & & & & & & & Guarantee ratio \\
\hline F a n g et al. [39] & & & & & & & & $\begin{array}{c}\text { Resource } \\
\text { capacity ratio }\end{array}$ \\
\hline Li et al. [40] & & & & & & & $\checkmark$ & \\
\hline $\begin{array}{l}\text { Chandrasekaran, } \\
\text { Muralidh ar and } \\
\text { Dixit [41] }\end{array}$ & & & & & & & & Machining cost \\
\hline S u n et al. [43] & & & & & $\checkmark$ & $\checkmark$ & & \\
\hline $\mathrm{H} \mathrm{u}$ a $\mathrm{ng}$ et al. [45] & & & & & & & & $\begin{array}{c}\text { Total delay } \\
\text { time, Service } \\
\text { capacity }\end{array}$ \\
\hline Li u et al. [47] & $\checkmark$ & & $\checkmark$ & & & & & - \\
\hline $\begin{array}{l}\text { A b d u lla hi, N gadi } \\
\text { and A b d u l ha mid } \\
{[48]}\end{array}$ & $\checkmark$ & $\checkmark$ & & & & & & $\begin{array}{l}\text { Degree of } \\
\text { imbalance }\end{array}$ \\
\hline Zineddine $[50]$ & & & & & & & & Cost of loss \\
\hline
\end{tabular}


In [43] the throughput stepping plan is automatically derived from the particular throughput QoS goals. The Communication to computation ratio is able to be used to point out whether a task graph is computation-intensive or communication intensive [3]. The energy consumption and makespan linked with the resources allocated have to be taken into account in the business application process of green cloud computing. Hence, resource allocation has to be vigilantly coordinated and optimized jointly in order to accomplish an energy-efficient schedule. The amount of time taken between submission of a request and the first response is called as Response time [13]. Response time has been used for cloud optimization in $10.3 \%$ of the collected optimization papers. Measures such as Throughput, CPU usage, flow time, energy consumption and Communication to computation ratio are used evenly in $34.5 \%$ of the total cloud optimization papers.

Flow time is represented as the sum of finalization times of all the tasks and it is expressed in Equation (9). The Communication to Computation Ratio (CCR) represents as the average edge weight divided by the average node weight. The CCR is represented in Equation (10) and it indicates the significance of the communication in a task graph that determines the scheduling behaviour.

$$
\begin{gathered}
F=\min _{S \in \text { Schedules }}\left\{\sum_{j \in \text { tasks }} C_{j}\right\}, \\
\mathrm{CCR}=\frac{\sum_{x, j} c(x, j) \times \text { number of nodes }}{\sum_{x} c n(x) \times \text { number of nodes }},
\end{gathered}
$$

where $c n(x)$ represents the computation cost of a node $x, c(x, j)$ represents the computation costs from node $x$ to node $j$, and $(x, j)$ indicates the nodes number, $C_{j}$ represents the time while task $j$ is finalized.

CPU usage is represented in Equation (11) and the energy consumption is calculated using Equation (12):

$$
\begin{gathered}
\mathrm{CPU}=\frac{C_{T_{w}}}{T_{t}}, \\
\Delta E=\sum_{i=10}^{m} \int_{0}^{t} f(t) c(t)-m P_{1} t,
\end{gathered}
$$

where $T_{w}$ indicates the waiting time by CPU for task and $T_{t}$ indicates the total job execution time, $P_{1}$ represents the peak power, $f$ represents the frequency of cloud computing nodes and $c$ is the utilization of computation nodes.

The Makespan is defined as a performance measure of the throughput of the heterogeneous grid environment. Moreover, it is a maximum time, which all the processor taken and it is calculated using next equation:

$$
M=\max (\mathrm{ETS}) \text {, }
$$

where

$$
\operatorname{ETS}=\left(\sum_{i=1 \text { to } X} \operatorname{ETX}\left(t_{1}\right), \operatorname{ETX}\left(t_{2}\right), \ldots, \operatorname{ETX}\left(t_{Y}\right)\right),
$$


The Response time is defined as the time interval between the first response and arrival time of a task. The Response time is calculated using Equation (15) and throughput is calculated using Equation (16):

$$
\begin{gathered}
R T=\left(\frac{1}{X}\right)_{i=1 \mathrm{to} X} 1 \text { st Response }- \text { Arrivaltime, } \\
\text { Throughput }=\frac{\text { Number of task }}{\text { time unit }},
\end{gathered}
$$

\section{Meta-heuristic procedures for Cloud optimization}

\subsection{Exploration of meta-heuristics for cloud optimization}

Meta-heuristic has been used to search optimal solutions in most of the problems in a cloud environment. To achieve better performance for most of the scheduling problems, meta-heuristic techniques are used. Recently, this approach is used to solve the NP-hard optimization problems.

Table III represents the role of meta-heuristic methods for cloud optimization. Form the tabulation; it has been found that a Genetic algorithm, PSO, and its variance were used widely for cloud optimization. Among all the papers reviewed, the usage of GA and PSO in cloud optimization was about $23.5 \%$ and $23.5 \%$, respectively. ACO algorithms are also exploited in meta-heuristic cloud optimization study, and it has been found to be $11.7 \%$. Most of the algorithms were used for solving the problem of task scheduling and service attacks. About $23.5 \%$ work has been done to solve the task scheduling problem, and $11.7 \%$ has been used in solving the service attack problem. Within the $23.5 \%$ of task scheduling approaches, $11.7 \%$ problem is solved with GA and another $11.7 \%$ with PSO.

\section{Review outcome}

\subsection{Case study}

The free cloud infrastructure availability may be misused for many malicious activities [54]. In cloud computing, the applications and data are relocated to the cloud, which paves the way for the hackers to scatter the data and information.

Case 1. In Mat Honan's case, the entire digital life was destroyed within 1 hour. His Twitter account was used to publish hate, racist and homophobic messages. His personal data was deleted completely from iPhone, iPad, and MacBook. The Google account was also deleted. The attacker accessed the Honan's amazon's account using the public information and found the last four digit of his credit card. To access the Apple ID, they use this information; his Gmail account was used for password recovery. Due to lack of cooperation within the technology industry and data management policies, the dilemma occurs [55].

Case 2. In Sony's case, 24.6 million PC gamers are affected which gives a strong blow to the company and the Cloud entertainment concept as a whole. The 
private and sensitive data of gamers are hacked and used this data to access the Sony's PC Games Network. The attack against Sony's network was due to a hacker renting service of Amazon Elastic Compute Cloud. The level of trust in Sony's PC Games Network and the Cloud technology as a whole was negatively impacted by the security breach against Sony [56]. The vulnerability used in this attack is not yet revealed.

Case 3. In Amazon's case, the hackers broke the Amazon's Cloud infrastructure by getting unauthorized access to Amazon's EC2 service by hacking a vulnerable website and secretly installing Zeus password-stealing botnet. However, the botnet on the cloud computing infrastructure was identified by the security researchers and removed [57]. The hacked companies did not disclose the vulnerability used by the hackers. The hackers may have obtained the administrative password by stealing and accessed the network. This has created some concerns because the Cloud Computing has been built on a resource sharing concept. Further, spammers have been using rented servers for their spam activities, and so a large portion of EC2 IP addresses was blacklisted [58].

Case 4. In Dropbox's case, the hackers obtained the passwords from other websites and used them for spamming and other illegal activities. The account information that is stored in the cloud is vulnerable. Dropbox users' logging credentials were hacked. Dropbox representatives acknowledged the breach and introduced new security measures to mitigate the problem.

Table 3. Role of meta-heuristic methods for cloud optimization

\begin{tabular}{|c|c|c|}
\hline Authors & Algorithm & Purpose \\
\hline $\mathrm{X} \mathrm{u}$ et al. [3] & $\begin{array}{l}\text { Chemical reaction } \\
\text { optimization }\end{array}$ & Formulating directed acrylic graph scheduling scheme \\
\hline $\begin{array}{l}\text { A. Kon a k, S. Kon a k and } \\
\text { S n y d e r [5] }\end{array}$ & $\begin{array}{l}\text { Game theoretic genetic } \\
\text { algorithm }\end{array}$ & $\begin{array}{l}\text { For reliable server assignment problem } \\
\text { under attack }\end{array}$ \\
\hline A h m a d et al. [6] & Hybrid genetic algorithm & Workflow scheduling problem \\
\hline B arati and Sharifian [7] & Support vector regression & Cloud load prediction \\
\hline $\mathrm{K}$ a r a $\mathrm{mi}$ and $\mathrm{Zap}$ a t a $[9]$ & $\begin{array}{l}\text { Radial basis function } \\
\text { particle swarm } \\
\text { optimization }\end{array}$ & Mitigating Denial of service attacks. \\
\hline B a m a k a $n$ et al. [11] & Particle swarm optimization & To improve the performance of MCLP classifier \\
\hline $\begin{array}{l}\text { Sh u, W. W a n g } \\
\text { and Y.W a n g [13] }\end{array}$ & Immune clonal optimization & Green cloud computing \\
\hline $\begin{array}{l}\text { Pacin i, } \\
\text { Mate os and } \\
\text { Garin o }[20]\end{array}$ & Ant colony optimization & $\begin{array}{l}\text { Balancing throughput and response time } \\
\text { in online scientific clouds }\end{array}$ \\
\hline S u gun a and S uhas in i [27] & Enriched genetic algorithm & For efficient disaster recovery in cloud environment \\
\hline P a $1 \mathrm{~m}$ i e r i et al. [30] & $\begin{array}{l}\text { Greedy randomized adaptive } \\
\text { search procedure }\end{array}$ & To tackle re-optimization problem \\
\hline $\begin{array}{l}\text { Ju l a, O th m a n, and } \\
\text { Sund araraj a n [33] }\end{array}$ & $\begin{array}{l}\text { Imperialist competitive } \\
\text { algorithm }\end{array}$ & $\begin{array}{l}\text { For service time optimization in cloud computing } \\
\text { service composition }\end{array}$ \\
\hline L u a and Yow [36] & $\begin{array}{l}\begin{array}{l}\text { Intelligent Water drop } \\
\text { algorithm }\end{array} \\
\end{array}$ & For distributed and parallel optimization \\
\hline W a n g et al. [38] & $\begin{array}{l}\text { Novel swarm intelligence } \\
\text { simulated algorithm }\end{array}$ & $\begin{array}{l}\text { Finding a solution to the problem of task scheduling in } \\
\text { integers and to formulate the swarm elite intelligence }\end{array}$ \\
\hline $\mathrm{H} \mathrm{u}$ a n g et al. [45] & Ant colony optimization & $\begin{array}{l}\text { To solve the multi-objective mathematical model of } \\
\text { conflict resolution }\end{array}$ \\
\hline L i u et al. [47] & Particle swarm optimization & $\begin{array}{l}\begin{array}{l}\text { Scheduling problem in work-flow applications } \\
\text { with security constraints }\end{array} \\
\end{array}$ \\
\hline $\begin{array}{l}\text { A bdullahi, Ngadi } \\
\text { and Abdulhamid [48] }\end{array}$ & $\begin{array}{l}\text { Discrete symbiotic genetic } \\
\text { search algorithm }\end{array}$ & For optimal scheduling of task on cloud resources \\
\hline Zineddine $[50]$ & $\begin{array}{l}\text { Cuckoo search algorithm } \\
\text { with Levy flight }\end{array}$ & Vulnerability coverage and cost optimization \\
\hline
\end{tabular}


A two-factor authentication, malicious activities' detection, and auditing features were introduced [59]. Various security measures have been implemented, but still looking for better secure systems.

\subsection{Research gaps and future directions}

For the past few decades, security issues in Information and Technology (IT) sector has been a concern. Many developments in software, hardware, and telecommunications had arrived in a fast and furious rate. The IT solutions are quite challenging the IT security dilemma because of its varied diversity and the complexity. Security vulnerabilities are spread widely. Approximately one hundred new security vulnerabilities are occurring weekly, which is reported by Computer Emergency Response Team [53]. Cloud computing has been a well-flourished area. However, the inherited traditional IT or Cloud IT security flaws within the Cloud should also be considered. The Data centres, which used to provide cloud computing services and implement super security solutions is a debatable thing in IT. To cover the identified vulnerabilities, the complex and dynamic cloud Computing environment shows novel approaches. Mitigation of identified security vulnerabilities by selecting the right set of security solutions has been a difficult task. New vulnerabilities had been introduced by some security solutions. These vulnerabilities are due to the coexistence of multiple security solutions. Therefore, the interactions between security technologies should be monitored and controlled. For security technologies, the budgets provided are finite. More ICT security professionals are needed to increase the ICT security vulnerabilities coverage with a reduction in operational cost. In addition, the IT security professionals use various tools and methodologies to prevent new vulnerabilities. To solve this problem, many algorithms such as genetic algorithm, cuckoo search, PSO, ACO and others combined with software such as MATLAB can be used.

\section{Summary}

In this paper, a various characteristic feature of the cloud environment and its various security challenges has been discussed and interpreted. The Cloud computing articles are chronologically reviewed in Section 2. From the review, it has been found that a contribution in cloud security was more. Various challenges and performance analysis of the cloud optimization is discussed in Section 3. Performance analysis study for cloud computing is tabulated and interpreted. It has been found that Makespan is used as the performance parameter for a lot of studies and it is about $31 \%$. From the study, it has been found that a lot of algorithms are used for solving the task scheduling problem. Section 4 interprets the meta-heuristic study in a cloud environment. Algorithms such as GA, PSO, and ACO had been used widely to challenge the cloud security attacks and workflow scheduling problems. Among all the papers reviewed, the usage of GA and PSO in cloud optimization was about $23.5 \%$ and $23.5 \%$, respectively. Section 5 reveals the four case studies which are related to the security challenges in the cloud computing environment. The future of 
cloud computing are wide and a lot of vulnerabilities have to be addressed more for reducing the security issues with low operational cost.

\section{References}

1. Karampaglis, Z., A. Gounaris, Y. Manolopoulos. A Bi-Objective Cost Model for Database Queries in a Multi-Cloud Environment. - Journal of Innovation in Digital Ecosystems, Vol. 1, December 2014, No 1-2, pp. 12-25.

2. Ch e n, Z., G. X u, V. M a h a 1 in g a m, L. G e, J. Ng u y e n, W. Y u, C. L u. A Cloud Computing Based Network Monitoring and Threat Detection System for Critical Infrastructures. Big Data Research, November 2015, In Press.

3. X u, Y., K. Li, L. H e, T. K. Tr u o n g. A DAG Scheduling Scheme on Heterogeneous Computing Systems Using Double Molecular Structure-Based Chemical Reaction Optimization. J. Parallel Distrib. Comput.,Vol. 73, September 2013, No 9, pp. 1306-1322.

4. H a n, Y., T. Alpc an, J. Chan, C. Leckie, B. I. P. Rubinstein. A Game Theoretical Approach to Defend Against Co-Resident Attacks in Cloud Computing: Preventing CoResidence Using Semi-Supervised Learning. - IEEE Transactions on information Forensics and Security, Vol. 11, March 2016, No 3, pp. 556-570.

5. Konak, A., S. K. Konak, L. V. Snyder. A Game-Theoretic Genetic Algorithm for the Reliable Server Assignment Problem under Attacks. - Computers \& Industrial Engineering, Vol. 85, July 2015, pp. 73-85.

6. Ahmad, S. G., C. S. Li e w, E. U. Munir, T. F. Ang, S. U. Khan. A Hybrid Genetic Algorithm for Optimization of Scheduling Workflow. - Applications in Heterogeneous Computing Systems, Vol. 87, January 2016, pp. 80-90.

7. B a r a t i, M., S. S h a r i f i a n. A Hybrid Heuristic-Based Tuned Support Vector Regression Model for Cloud Load Prediction. - J. Supercomput., Vol. 71, November 2015, No 11, pp. 4235-4259.

8. Che n, J. H., F. A be di n, K. M. Ch a o, N. Godwi n, Y. Li, C. F. T s a i. A Hybrid Model for Cloud Providers and Consumers to Agree on QoS of Cloud Services - Future Generation Computer Systems, Vol. 50, September 2014, pp. 38-48.

9. K a r a mi, A., M. G. Z a p a t a. A Hybrid Multiobjective RBF-PSO Method for Mitigating DoS Attacks in Named Data Networking. - Neurocomputing, Vol. 3, March 2015, No 3, pp. 1262-1282.

10. W u, Z., X. L i u, Z. N i, D. Y u a n, Y. Y a n g. A Market-Oriented Hierarchical Scheduling Strategy in Cloud Workflow Systems. - J. Supercomput, Vol. 63, January 2013, No 1, pp. 256-293.

11. B a ma k a n, S. M. H., B. A mi ri, M. M i r z ab a g h er i, Y. S hi. A New Intrusion Detection Approach Using PSO Based Multiple Criteria Linear Programming. - Procedia Computer Science, Vol. 55, 2015, pp. 231-237.

12. S ingh, A., D. Juneja, M. Malhotra. A Novel Agent Based Autonomous and Service Composition Framework for Cost Optimization of Resource Provisioning in Cloud Computing. - Journal of King Saud University - Computer and Information Sciences, Vol. 29, 2017, No 1, pp. 19-28.

13. S h u, W., W. W a n g, Y. W a n g. A Novel Energy-Efficient Resource Allocation Algorithm Based on Immune Clonal Optimization for Green Cloud Computing. - EURASIP Journal on Wireless Communications and Networking, Vol. 64, December 2014.

14. K o e h 1 e r, M. An Adaptive Framework for Utility-Based Optimization of Scientific Applications in the Cloud. - Journal of Cloud Computing, Vol. 3, December 2014, No 4.

15. Li u, Q., C. W e n g, M. Li, Y. L u o. An In-VM Measuring Framework for Increasing Virtual Machine Security in Clouds, Vol. 8, November 2010, No 6, pp. 56-62.

16. Ji a n g, D., Z. X u, J. Li u, W. Z h a o. An Optimization-Based Robust Routing Algorithm to Energy-Efficient Networks for Cloud Computing. - Telecommun. Syst., March 2015, pp. 1-10. 
17. Grzonka, D., J. Kołodziej, J. Ta o, S. U. Khan. Artificial Neural Network Support to Monitoring of the Evolutionary Driven Security Aware Scheduling in Computational Distributed Environments. - Future Generation Computer Systems, Vol. 51, October 2015, pp. 72-86.

18. Folin o, G., F. S. Pis an i. Automatic Offloading of Mobile Applications into the Cloud by Meansof Genetic Programming. - Applied Soft Computing, Vol. 25, December 2014, pp. 253-265.

19. S in g h, A., D. J u n e j a, M. M a 1 h ot $\mathrm{r}$ a. Autonomous Agent Based Load Balancing Algorithm in Cloud Computing. - Procedia Computer Science, Vol. 45, 2015, pp. 832-841.

20. P a c i n i, E., C. M a t e o s, C. G. G a r i n o. Balancing Throughput and Response Time in Online Scientific Clouds via Ant Colony Optimization (SP2013/2013/00006). - Adv. Eng. Softw., Vol. 84, June 2015, pp. 31-47.

21. L i n, H., J. S h a o, C. Z h a n g, Y. F a n g. CAM: Cloud-Assisted Privacy Preserving Mobile Health Monitoring. - IEEE Transactions on Information Forensics and Security, Vol. 8, June 2013, No 6, pp. 985-997.

22. Mogh a dd a m, F. F., R. F. Mogh a d d a m, M. Ch e ri e t. Carbon-Aware Distributed Cloud: Multi-Level Grouping Genetic Algorithm. - Cluster Computing, Vol. 18, March 2015, No 1, pp. 477-491.

23. M a m u n, K. A. A., M. A 1 h u s s e i n, K. S a i 1 u n a z, M. S. I s 1 a m. Cloud Based Framework for Parkinson's Disease Diagnosis and Monitoring System for Remote Healthcare Applications. - Future Generation Computer Systems, November 2015 (In Press).

24. Ar a n g o a, I. M., J. S. I zqui erd o, E. O. G. C a m p be 11, R. P. G a r c i a b. Cloud-Based Decision Making in Water Distribution Systems. - Procedia Engineering, Vol. 89, 2014, pp. 488-494.

25. A 1 kh a n a k, E. N., S. P. Le e, R. R e z a i, R. M. P a ri zi. Cost Optimization Approaches for Scientific Workflow Scheduling in Cloud and Grid Computing: A Review, Classifications, and Open Issues. - Journal of Systems and Software, Vol. 113, March 2016, pp. 1-26.

26. H u o, Y., Y. Zhu an g, J. J. Gu, S. N i, Y. X u e. Discrete Gbest-Guided Artificial Bee Colony Algorithm for Cloud Service Composition. - Appl Intell, Vol. 42, June 2015, No 4, pp. 661-678.

27. S u g u n a, S., A. S u h a s in i. Enriched Multi Objective Optimization Model Based Cloud Disaster Recovery. - Karbala International Journal of Modern Science, Vol. 1, October 2015, No 2, pp. 122-128.

28. N a vi m i p o u r, N. J., A. M. R a h m a n i, A. H. N a vi n, M. Ho s s e i n z a d e h. Expert Cloud: A Cloud-Based Framework to Share the Knowledge and Skills of Human Resources. Computers in Human Behavior, Vol. 46, 2015, pp. 57-74.

29. Z h u, S., G. G on g. Fuzzy Authorization for Cloud Storage. - IEEE Transactions on Cloud Computing, Vol. 2, July 2014, No 4, pp. 422-435.

30. Palmi eri, F., U. Fi ore, S. Ric ci ardi, A. Castigli on e. GRASP-Based Resource ReOptimization for Effective Big Data Access in Federated Clouds. - Future Generation Computer Systems, Vol. 54, January 2016, pp. 168-179.

31. B i t t e n c o u r t, L. F., E. R. M. M a d e i r a. HCOC: A Cost Optimization Algorithm for Workflow Scheduling in Hybrid Clouds. - J. Internet Serv Appl., Vol. 2, 2011, No 3, pp. 207-227.

32. R a o, K. S., P. S. Th il a g a m. Heuristics Based Server Consolidation with Residual Resource Defragmentation in Cloud Data Centers. - Future Generation Computer Systems, Vol. 50, September 2015, pp. 87-98.

33. J u 1 a, A., Z, O th m a n, E. S u n d a r a r a j a n. Imperialist Competitive Algorithm with PROCLUS Classifier for Service Time Optimization in Cloud Computing Service Composition. - Expert Systems with Applications, Vol. 42, January 2015, No 1, pp. 135-145.

34. Hu u, T. T., G. Koslovski, F. Anhalt, J. Montagnat, P. V. B. Primet. Joint Elastic Cloud and Virtual Network Framework for Application Performance-Cost Optimization. J. Grid Computing, Vol. 9, March 2011, No 1, pp. 27-47.

35. G e, X., B. Y a o, M. G u o, C. L. X u. LSShare: An Efficient Multiple Query Optimization System in the Cloud. - Distrib. Parallel Databases, Vol. 32, December 2014, No 4, pp. 583-605.

36. L u a, R., K. C. Y o w. Mitigating DDoS Attacks with Transparent and Intelligent Fast-Flux Swarm Network. - IEEE Network, Vol. 25, July-August 2011, No 4, pp. 28-33. 
37. Y i ld i r i m, E., J. K i m b, T. K o s a r. Modeling Throughput Sampling Size for a Cloud-Hosted Data Scheduling and Optimization Service. - Future Generation Computer Systems, Vol. 29, September 2013, No 7, pp. 1795-1807.

38. W a n g, J., B. G o n g, H. L i u, S. L i. Multidisciplinary Approaches to Artificial Swarm Intelligence for Heterogeneous Computing and Cloud Scheduling. - Appl. Intell., Vol. 43, October 2015, No 2, pp. 662-675.

39. F a n g, D., X. Li u, L. Li u, H. Y an g. OCSO: Off-the-Cloud Service Optimization for Green Efficient Service Resource Utilization. - Journal of Cloud Computing: Advances, Systems and Applications, Vol. 3, December 2014, No 9.

40. Li, J., M. Qi u, Z. Ming b, G. Qu an, X. Q i n, Z. Gu. Online Optimization for Scheduling Preemptable Tasks on IaaS Cloud Systems. - J. Parallel Distrib. Comput., Vol. 72, May 2012, No 5, pp. 666-677.

41. Ch a $\mathrm{dr}$ a se k ar a n, M., M. M u ra li d har, U.S. D ix i t. Online Optimization of Multipass Machining Based on Cloud Computing. - Int. J. Adv. Manuf. Technol., Vol. 65, March 2013, No 1, pp. 239-250.

42. S h i, Y., W. W. B o. Physical Layer Security Strategies for Downlink Heterogeneous Cloud Radio Access Networks. - The Journal of China Universities of Posts and Telecommunications, Vol. 21, October 2014, No 5, pp. 47-54

43. S u n, Y., J. Wh it e, S. E a d e, D. C. S c h mid t. ROAR: AQoS-Oriented Modeling Framework for Automated Cloud Resource Allocation and Optimization. - Journal of Systems and Software, 2015.

44. Zeng, L., B. V e eravalli, X. Li. SABA: A Security-Aware and Budget-Aware Workflow Scheduling Strategy in Clouds. - J. Parallel Distrib. Comput., Vol. 75, January 2015, pp. 141-151.

45. H u a n g, X., B. D u, L. S u n, F. C h e n, W. D a i. Service Requirement Conflict Resolution Based on Ant Colony Optimization in Group-Enterprises-Oriented Cloud Manufacturing. - Int. J. Adv. Manuf. Technol., October 2015, pp. 1-14.

46. S i n d h u, R., H. K. G i 1 1, S. K. S o o d. Smart Monitoring and Controlling of Pandemic Influenza A (H1N1) Using Social Network Analysis and Cloud Computing. - Journal of Computational Science January 2016, pp. 11-22.

47. Li u, H., A. Abrah a m, V. S n a s e l, S e an Mc Loone. Swarm Scheduling Approaches for Work-Flow Applications with Security Constraints in Distributed Data-Intensive Computing Environments. - Information Sciences, Vol. 192, June 2012, pp. 228-243.

48. Abdullahi, M., M. A. Ngadi, S. M. Abdulhamid. Symbiotic Organism Search Optimization Based Task Scheduling in Cloud Computing Environment. - Future Generation Computer Systems, Vol. 56, March 2016, pp. 640-650.

49. Mehrotra, R., S. S rivast a va, I. B a n i c e s c u, S. A b d e l w a h e d. Towards an Autonomic Performance Management Approach for a Cloud Broker Environment Using a DecompositionCoordination Based Methodology. - Future Generation Computer Systems, Vol. 54, January 2016, pp. 195-205.

50. Zin eddine, M. Vulnerabilities and Mitigation Techniques Toning in the Cloud A Cost and Vulnerabilities Coverage Optimization Approach Using Cuckoo Search Algorithm with Levy Flights. - Conputer Security, Vol. 48, 2015.

51. S in g h, A., M. M a $1 \mathrm{~h}$ o $\mathrm{tr}$ a. Analysis for Exploring Scope of Mobile Agents in Cloud Computing. - Int. J. Adv. Technol., Vol. 3, 2012, No 3.

52. M e 11, P., T. Gra n c e. Perspectives on Cloud Computing and Standards. National Institute of Standards and Technology (NIST), Information Technology Laboratory, 2009.

53. CERT. Retrieved January 2013. http://www.cert.org/

54. T e n d u l k a r, V., J. P l e t c h e r, A. S h a s h i d h a r a n. Abusing Cloud-Based Browsers for Fun and Profit. - In: Proc. of 28th Annual Computer Security Applications Conference, New York, NY, USA, ACM, 2012, pp. 219-228.

55. R a c o m a, J. A. "Epic Hacking" Incident Brought about by Apple, Amazon Cloud Security Flaws. Retrieved December 2012.

http://www.cmswire.com/cms/information-management/epic-hacking-incident-broughtabout-by-apple-amazoncloud-security-flaws-016845.php; 2012 
56. K e n n e d y, J. Latest Cyber Attack on Sony a Breach Too Far for Entire Cloud Industry. Retrieved December 2012.

http:// siliconrepublic.com/cloud/item/21613-latest-cyber-attack-onsony; 2011

57. M i 11 a n, R. M. Hackers Find a Home in Amazon's EC2 Cloud, Retrieved December 2012. http://www.infoworld.com/d/cloud-computing/hackers-find-home-in-amazons-ec2cloud-742, 2009.

58. Ch e n, Y., V. P a x s o n, R. K a tz. What's New About Cloud Computing Security? Tech. Rep. No UCB/EECS-2010-5, Berkeley, 2010.

59. B a r r o n, C., H. Y u, J. Z h a n. Cloud Computing Security Case Studies and Research. - In: Proc. of World Congress on Engineering, Vol. II, 2013, London, UK.

60. W o o d, R. K. Deterministic Network Interdiction. - Mathematical and Computer Modelling, Vol. 17, January 1993, No 2, pp. 1-18.

61. S m i t h, J. C., C. L i m, F. S u d a r g h o. Survivable Network Design under Optimal and Heuristic Interdiction Scenarios. - Journal of Global Optimization, Vol. 38, June 2007, No 2, pp. 181-199.

62. A kgu n, L., B. C. T a n s e 1, R. K. W o o d. The Multi-Terminal Maximum-Flow NetworkInterdiction Problem. - European Journal of Operational Research, Vol. 211, June 2011, No 2, pp. 241-251.

63. M a rque z, J. E. R., C. M. R o c c o, G. Le viti n. Optimal Network Protection against Diverse Interdictor Strategies. - Reliability Engineering \& System Safety, Vol. 96, March 2011, No 3, pp. 374-382.

64. Marquez, J. E. R., S. C. M. R oc co. Stochastic Network Interdiction Optimization via Capacitated Network Reliability Modeling and Probabilistic Solution Discovery. - Reliability Engineering \& System Safety, Vol. 94, May 2009, No 5, pp. 913-921.

65. C a l v e t e, H. L., C. G a l e, P. M. M a t e o. A New Approach for Solving Linear Bilevel Problems Using Genetic Algorithms. - European Journal of Operational Research, Vol. 188, July 2008, No 1, pp. 14-28.

66. He jazi, S. R., A. Me mariani, G. Jah anshahloo, M. M. S e pehri. Linear Bilevel Programming Solution by Genetic Algorithm. - Computers \& Operations Research, Vol. 29, November 2002, No 13, pp. 1913-1925.

67. M a th i e u, R., L. P itt a rd, G. An and a ling a m. Genetic Algorithm Based Approach to BiLevel Linear Programming. - RAIRO Recherche Operationnelle, Vol. 28, 1994, No 1, pp. 1-21.

68. W a n g, G. M., X. J. W a n g, Z. P. W a n, S. H. J i a. An Adaptive Genetic Algorithm for Solving Bilevel Linear Programming Problem. - Applied Mathematics and Mechanics, Vol. 28, December 2007, pp. 1605-1612.

69. W a n g, G. M., Z. P. W a n, X. J. W a n g, Y. L. Ch e n. Genetic Algorithms for Solving Linear Bilevel Programming. - In: 6th International Conference on Parallel and Distributed Computing, Applications and Technologies, IEEE, December 2005, pp. 920-924.

70. K i m, J. R., J. U. L e e, J. B. J o. Hierarchical Spanning Tree Network Design with Nash Genetic Algorithm. - Computers \& Industrial Engineering, Vol. 56, April 2009, No 3, pp. 1040-1052.

71. Lee, J., B. Tierney, W. Johnston. Data Intensive Distributed Computing: A Medical Application Example. - Lecture Notes in Computer Science, Vol. 1593, 1999, pp. 150-158.

72. Hor n, W. AI in Medicine on Its Way from Knowledge-Intensive to Data-Intensive Systems. Artificial Intelligence in Medicine, Vol. 23, August 2001, No 1, pp. 5-12.

73. Z hon g, N., J. H u, S. M o t o m u r a, J. W u, C. Li u. Building a Data-Mining Grid for Multiple Human Brain Data Analysis. - Computational Intelligence, Vol. 21, May 2005, No 2, pp. 177-196.

74. B o c c i a, A., G. B u si e 11 o, L. Mil a n e s i, G. P a o l e 11 a. A Fast Job Scheduling System for a Wide Range of Bioinformatic Applications. - IEEE Transactions on NanoBioscience, Vol. 6, June 2007, No 2, pp. 149-154.

75. Hey, T., S. Tan sle y, K. Tolle. The Fourth Paradigm: Data-Intensive Scientific Discovery. Microsoft Research, 2009.

76. Eberhart, R., Y. Shi. Comparison between Genetic Algorithms and Particle Swarm Optimization. - In: Lecture Notes in Computer Science, Vol. 1447, 1998, pp. 611-618. 
77. B o e ring er, D., D. W e rn er. Particle Swarm Optimization Versus Genetic Algorithms for Phased Array Synthesis. - IEEE Transactions on Antennas and Propagation, Vol. 52, April 2004, No 3, pp. 771-779.

78. Abraham, A., H. Guo, H. Liu. Swarm Intelligence: Foundations, Perspectives and Applications. - Swarm Intelligent Systems, Studies in Computational Intelligence, Vol. 26, 2006, pp. 3-25.

79. D a s, S., A. A b r a h a m, A. K on a r. Automatic Kernel Clustering with a Multi-Elitist Particle Swarm Optimization Algorithm. - Pattern Recognition Letters, Vol. 29, April 2008, No 5, pp. 688-699.

80. Li u, H., A. A b r a h a m, Z. W ang. A Multi-Swarm Approach to Multi-Objective Flexible JobShop Scheduling Problems. - Fundamenta Informaticae, Vol. 95, 2009, 2009, pp. 1-25.

81. R as h i d i, M. R. A., M. E. E. H a w a r y. A Survey of Particle Swarm Optimization Applications in Electric Power Systems. - IEEE Transactions on Evolutionary Computation, Vol. 13, August 2009, No 4, pp. 913-918.

82. B a b a o g lu, I., O. Findik, E. I 1 ke r. A Comparison of Feature Selection Models Utilizing Binary Particle Swarm Optimization and Genetic Algorithm in Determining Coronary Artery Disease Using Support Vector Machine. - Expert Systems with Applications, Vol. 37, April 2010, No 4, pp. 3177-3183.

83. S u n d a r, S., A. S in g h. A Swarm Intelligence Approach to the Quadratic Minimum Spanning Tree Problem. - Information Sciences, Vol. 180, September 2010, No 17, pp. 3182-3191.

84. C a o, J., J. C h e n, Q. Z h a o. An Optimized Scheduling Algorithm on a Cloud Workflow Using a Discrete Particle Swarm. - Cybernetics and Information Technologies, Vol. 14, March 2014, No 1, pp. 25-39.

85. C h. N., S. N. I y e n g a r, G. G a n a p a th y. Trilateral Trust Based Defense Mechanism against DDoS Attacks in Cloud Computing Environment. - Cybernetics and Information Technologies, Vol. 15, July 2015, No 2, pp. 119-140.

86. J e y a $\mathrm{th}$ i, N., P. C. Mog an kumar. A Virtual Firewall Mechanism Using Army Nodes to Protect Cloud Infrastructure from DDoS Attacks. - Cybernetics and Information Technologies, Vol. 14, September 2014, No 3, pp. 71-85.

87. Govinda, K., E. S athiyamoorthy. Privacy Preservation of a Group and Secure Data Storage in Cloud Environment. - Cybernetics and Information Technologies, Vol. 15, March 2015, No 1, pp. 46-54.

88. B r in d h a, K., N. J e y a $\mathrm{t} \mathrm{h}$ i. Secured Document Sharing Using Visual Cryptography in Cloud Data Storage. - Cybernetics and Information Technologies, Vol. 15, November 2015, No 4, pp. 111-123.

89. V o 11 a n d, J., A. F u g e n e r, J. O. B r u n n e r. A Column Generation Approach for the Integrated Shift and Task Scheduling Problem of Logistics Assistants in Hospitals. - European Journal of Operational Research, Vol. 260, July 2017, pp. 316-334.

90. $\mathrm{K} \mathrm{u} \mathrm{z} \mathrm{m}$ a n o v i c, A., E. W. K n i g h t l e y. Low-Rate TCP-Targeted Denial of Service Attacks. In: Proc. of Conference on Applications, 2003, pp. 75-86. 